\title{
Cognitive and Affective Perspective-Taking Ability of Young Bilinguals in South Korea
}

\author{
Sinae Han* \\ Kangyi Lee \\ Seoul National University
}

\begin{abstract}
The present study examined balanced bilingual children's cognitive and affective perspectivetaking and compared them to that of monolingual children. A total of 133 children aged 4 to 5 years and consisting of 73 Korean-English bilinguals and 60 Korean monolinguals were tested with cognitive perspective-taking and affective perspective-taking tasks. Balanced bilinguals were screened through general language ability tests in both English and Korean. Participant backgrounds were collected through a parent questionnaire. Results showed significant differences in affective perspective-taking between bilingual and monolingual children, demonstrating that bilingual children outperformed monolingual children. Although there was no difference in cognitive perspective-taking between bilinguals and monolinguals, the result showed that children's cognitive perspective-taking ability develops with age. This study provides basic information about bilingual children's perspective-taking ability and their bilingual advantage.
\end{abstract}

Keywords: bilingualism, balanced bilinguals, cognitive perspective-taking ability, affective perspective-taking ability

Perspective-taking is explicitly socialinterpersonal in that it requires the ability to infer another's capabilities, attributes, expectations, feelings, and potential reactions. Perspectivetaking not only influences a child's psychological development, but also influences development of social cognitive functions such as referential communication, understanding other's emotions, self concept and self-esteem, interpersonal perception, and inferring other's intentions (Berk, 2000). In consideration of this, perspectivetaking may have some relation with the development of a child's social competence. However, taking another's perspective implies

This research was poster presented at the 2010 Spring Conference of the Korean Association of Child Studies and was part of the author's master thesis in 2008 .

* Corresponding Author: Sinae Han, Department of Child Development and Family Studies, Building 222, Seoul National University, 1 Gwanak-ro, Gwanak-gu, Seoul 151-742, S. Korea, Email: sinae_han80@hotmail.com the ability to differentiate the other's view from one's own, and the ability to shift, balance, and evaluate both perceptual and cognitive object input (Kurdek \& Rodgon, 1975; Perner, 1983), all of which is clearly cognitive. In respect to the development of perspective-taking ability, previous research evidence suggests a possible connection between the use of bilingualism and perspective-taking. The evidence points out that bilingualism helps develop representational skills (Vygotsky, 1962), improves a child's executive function operation (Bialystok, 2001; Lee, Jeon, \& Park, 2003), and helps develop social language skills (Lanza, 1992), which may be related to the development of a child's perspective-taking ability.

Early studies on bilingualism supported negative bilingualism, i.e., that bilingualism hindered children's cognitive development (Ausubel, Sullivan, \& Ives, 1980; Darcy, 1953). 
According to these studies, bilingualism was said to hamper a child's development of intelligence and to lead children to psychological confusion than that of monolingual children (Laurie 1890; Saer, 1923; Smith, 1923). However, over the years, the perspective of how bilingualism affects cognitive functioning has changed and the early studies were criticized for a methodological flaw of not controlling for the socioeconomic status (SES) level of comparison groups (Peal \& Lambert, 1962). Peal and Lambert's study showed a positive effect of bilingualism on children's cognitive development and this influenced researchers to investigate the positive side of bilingualism. With controlled SES groups, researchers began to prove that bilingual children have higher executive function operation (Bialystok, 2001; Lee, Jeon, \& Park, 2003), better analogical reasoning (Diaz, 1985), cognitive flexibility (Ricciardelli, 1992), and perform better in problem solving and finding rules (Bain, 1975). In particular, a large number of studies found that balanced bilingual children show advantages in measures of metalinguistics awareness (Bialystok \& Codd, 1997; Galambos \& GoldinMeadow, 1990; Garcia, 2000; Nam, 2003; Yelland, Pollard, \& Mercuri, 1993).

In contrast, there are relatively no studies directly comparing perspective-taking ability and childhood bilingualism. However, their relationship can be inferred from some of the evidence taken from studies on bilinguals' theory of mind. Theory of mind is an essential developmental skill that children need to interact with others. Researches that examined theory of mind with bilingualism (Goetz, 2003; Lee \& Lee, 2006), revealed that bilingual children demonstrated better achievement on theory of mind tasks than monolingual children. From this evidence, we can infer that bilingual experience may be related to the development of theory of mind.

Possible factors contributing to bilingual children's advantage in theory of mind tasks are a metalinguistic advantage which may aid in developing representational abilities, greater linguistic control over conflicting representations which may produce a greater inhibitory control, and greater sociolinguistic awareness of the need to note their conversational partners' linguistic knowledge (Goetz, 2003). According to Goetz (2003), greater metalinguistic abilities of bilinguals may have been possible because bilingual children recognized that one object can be linguistically represented in two ways. From an early age, bilingual children encounter arbitrariness of language and this experience helps them to acquire metarepresentation-the understanding that one object can be represented differently by different people. A possible explanation for greater inhibitory control of bilinguals is that they need a higher level of control over their selective attention when faced with conflicting representation. Lastly, bilinguals recognize the need to match their language to that of their partner's with a growing knowledge that the partner's language can be different from their own. This experience allows them to be more aware of social language.

In a similar context, differences may exist in perspective-taking ability between bilingual children and monolingual children. The three advantages of bilingual children explained above are also factors that can help develop children's perspective-taking ability. Development of representational ability, inhibitory control, and social knowledge are key factors for children to decenter themselves and have the ability to acknowledge other's perspectives. Development of representation enables a child to understand that other perspectives exist, and children with greater inhibitory control are more successful in conflicting tasks. Lastly, higher social knowledge by bilingual children also has possible influence over perspective-taking tasks that require understanding of other's intentions and thoughts. For a successful perspective-taking task, children need to understand representation that is different from their own (Harwood \& Farrar, 2006); many researchers support the theory that children begin to understand the existence of more than one representation as their representational ability develops (Flavell \& Miller, 1998; Gopnik \& Wellman, 1994; Perner, 1991). Building on these findings, we can 
hypothesize the difference in perspective-taking ability between bilingual children and monolingual children.

To date, most studies focusing on bilingual children's language and cognitive development have been conducted in the United States where a bilingual environment is common. According to Bronfenbrenner's ecological theory (1979), child development is affected by its surrounding environment and children develop through interacting with every contact they make. Results from studies conducted in the United States, however, may not represent the developmental differences by bilingualism in South Korea. A child's growth environment is a key influential factor in child's language development (Templin, 1957), which is affected by the country's cultural context. Based on this, aspects of culture, social status, and gender should be considered (Roopnarine, Lasker, Sacks, \& Stores, 1998) when conducting a study on child language and cognitive development because cross-cultural differences may exist.

Until recently, domestic studies on bilingual children (Nam, 2003; Lee, Jeon, \& Park, 2003; Hwang \& Hwang, 2000; Hwang, 2007) have been comparison studies between Korean bilingual children living abroad and their monolingual counterparts or comparison studies between experienced English-speaking children who have prior English education and novice English-speaking children who have no prior English education. However, to simply consider Korean children living abroad as bilinguals and children living in South Korea as monolinguals may hinder research results since it would reflect differences in educational or cultural experience or socio-demographic differences rather than the bilingualism variable. In addition, children with early English educational experience cannot, in a strict sense, represent the true meaning of bilinguals. Thus, we should define bilingual children and monolingual children with a stricter standard for a more accurate measurement of the developmental differences in bilingualism.

Based on the results of prior studies (Doherty \& Perner, 1998; Flavell, 1968; Wellman, Phillips, \& Rodriguez, 2000) which show that perspective-taking ability develops during early childhood, the present study has the following goals. First, we will examine the cognitive and the affective perspective-taking ability of 4 and 5 -year-old balanced bilinguals in South Korea depending on age and gender. Building on from previous findings, we focus on balanced bilinguals who have sufficient knowledge in both Korean and English. Second, we also aim to compare cognitive perspective-taking ability and affective perspective-taking ability of bilingual children to that of monolingual children in South Korea and investigate whether differences exist between them.

\section{Method}

\section{Participants}

A total of 133 children participated in the present study. 73of the children were bilingual Korean-English speakers and 60 of the children were monolingual Korean speakers. All participants were currently living in the Seoul metropolitan area and Busan, South Korea. Half the children in each language group were 4-yearolds and half were 5 -year-olds. For the bilingual group, 354 -year-olds (14 boys and 21 girls) and 38 5-year-olds (16 boys and 22 girls) were recruited. In terms of age, 4-year-olds had a mean age of 48 months (ranging from 38 to 59 months) and the 5-year-olds had a mean age of 66 months (ranging from 60 to 79 months). For the monolingual group, 25 4-year-olds (14 boys and 11 girls) and 355 -year-olds (18 boys and 17 girls) were recruited. In terms of age, 4-year-olds had a mean age of 52 months (ranging from 42 to 59 months) and the 5-year-olds had a mean age of 69 months (ranging from 60 to 82 months).

In the present study, we used a stricter standard for defining bilingual children. Therefore we recruited Korean children speaking both Korean and English at age appropriate levels from several international schools/ kindergartens in South Korea (see Table 1 for a summary of the demographic characteristics of 


\section{Han \& Lee}

Table 1

Demographic Characteristics of Bilingual Children

\begin{tabular}{|c|c|c|}
\hline Variable & Type & Frequency $(\%)$ \\
\hline \multirow{10}{*}{ Place of Birth } & South Korea & $30(41.1)$ \\
\hline & Overseas & $43(58.9)$ \\
\hline & U.S.A. & $34(79.1)$ \\
\hline & Australia & $2(4.7)$ \\
\hline & Hong Kong & $2(4.7)$ \\
\hline & Taiwan & $1(2.3)$ \\
\hline & Japan & $1(2.3)$ \\
\hline & Kenya & $1(2.3)$ \\
\hline & France & $1(2.3)$ \\
\hline & The Philippines & $1(2.3)$ \\
\hline \multirow{5}{*}{ Overseas Experience } & Less than 1 year & $40(54.8)$ \\
\hline & $1-2$ years & $17(23.3)$ \\
\hline & 2-3years & $5(6.8)$ \\
\hline & $3-4$ years & $6(8.2)$ \\
\hline & More than 4 years & $5(6.8)$ \\
\hline \multirow{3}{*}{ Father's Education } & High school diploma & $0(0)$ \\
\hline & Bachelor's degree & $33(45.2)$ \\
\hline & Master's degree or above & $40(54.8)$ \\
\hline \multirow{3}{*}{ Mother's Education } & High school diploma & $1(1.4)$ \\
\hline & Bachelor's degree & $54(74.0)$ \\
\hline & Master's degree or above & $18(24.7)$ \\
\hline \multirow{4}{*}{ Father's Occupation } & Private business & $7(9.6)$ \\
\hline & Office job & $25(34.3)$ \\
\hline & Professional job & $32(43.8)$ \\
\hline & Others & $9(12.3)$ \\
\hline \multirow{5}{*}{ Mother's Occupation } & House wife & $48(65.8)$ \\
\hline & Private business & $4(5.5)$ \\
\hline & Office job & $4(5.5)$ \\
\hline & Professional job & $12(16.4)$ \\
\hline & Others & $5(6.8)$ \\
\hline \multirow{4}{*}{ Monthly Income } & Below 2 million won & $0(0)$ \\
\hline & $2-4$ million won & $8(11.0)$ \\
\hline & 4-6 million won & $21(28.8)$ \\
\hline & Above 6 million won & $44(60.3)$ \\
\hline
\end{tabular}


Table 2

Demographic Characteristics of Monolingual Children

\begin{tabular}{|c|c|c|}
\hline Variable & Type & Frequency $(\%)$ \\
\hline \multirow{2}{*}{ Place of Birth } & South Korea & $60(100.00)$ \\
\hline & Overseas & $0(0.00)$ \\
\hline \multirow{3}{*}{ Father's Education } & High school diploma & $2(3.3)$ \\
\hline & Bachelor's degree & $42(70.0)$ \\
\hline & Master's degree or above & $16(26.7)$ \\
\hline \multirow{3}{*}{ Mother's Education } & High school diploma & $4(6.6)$ \\
\hline & Bachelor's degree & $46(76.7)$ \\
\hline & Master's degree or above & $10(16.7)$ \\
\hline \multirow{4}{*}{ Father's Occupation } & Private business & $8(13.3)$ \\
\hline & Office job & $32(53.4)$ \\
\hline & Professional job & $16(26.7)$ \\
\hline & Others & $4(6.7)$ \\
\hline \multirow{5}{*}{ Mother's Occupation } & House wife & $41(68.3)$ \\
\hline & Private business & $2(3.3)$ \\
\hline & Office job & $9(15.0)$ \\
\hline & Professional job & $7(11.6)$ \\
\hline & Others & $1(1.7)$ \\
\hline \multirow{4}{*}{ Monthly Income } & Below 2 million won & $0(0)$ \\
\hline & $2-4$ million won & $8(13.3)$ \\
\hline & 4-6 million won & $26(43.3)$ \\
\hline & Above 6 million won & $26(43.3)$ \\
\hline
\end{tabular}

the sample). In order to control other environmental factors between the comparison groups, we restricted parents of bilingual participants to Korean only. Thus, KoreanEnglish bilingual children whose parents were non-Korean were excluded in the study. Bilingual children were tested with the Korean Picture Vocabulary Test (Kim, Chang, Lim, \& Baek, 1995), which was revised from the PPVT$\mathrm{R}$ and Peabody Picture Vocabulary Test $3^{\text {rd }}$ edition (Dunn \& Dunn, 1997) to measure their fluency in both languages. Five other bilingual children were tested, but were excluded from the study because they failed to meet the standards for being balanced bilinguals. Families of the bilingual group were middle class or above. In the study, monolingual children were recruited from kindergartens in a middle class neighborhood to control two groups' SES level (see Table 2 for a summary of the demographic 
characteristics of the sample). They were also tested with the Korean Picture Vocabulary Test and English PPVT- $3^{\text {rd }}$ edition to screen out possible balanced bilinguals in the group. Some of the children had some level of English input, but not sufficient enough to be bilinguals. In sum, the results confirmed that children were all Korean monolingual speakers.

\section{Measures}

General language ability test. In order to examine participants' general language ability in both Korean and English, the general language ability of all the children was measured by the Korean Picture Vocabulary Test, revised from PPVT-R, and English PPVT-3 ${ }^{\text {rd }}$ edition. Both tests were examined on the same day. Bilingual samples that did not meet the standard to be balanced bilingual were excluded in the analysis.

Cognitive perspective-taking task. All children were tested with a cognitive perspective-taking task derived from Flavell (1968) and developed by Kurdek and Rodgon (1975). The test consisted of seven pictures with a story in sequence. The story is about a main character (a boy or a girl) who is chased by a dog and climbs a tree to run away from the dog. The main character was either a boy or a girl depending on the testee's gender. Pictures used in the test were drawn by a professional illustrator. The tester placed seven pictures in a sequential order and asked the child to look at the pictures and tell the story in order. Then, the tester removed three pictures with the dog in it and asked the child how his/her friend would tell the story if the friend saw only these four pictures. For the final question, the child was asked what the friend would think the main character was doing in the tree and what the dog was doing in the last picture. The score was given when the child retold the story from the friend's perspective. The scores ranged from 0 to 2; the higher the point, the higher the child's cognitive perspective-taking ability.

Affective perspective-taking task. All children were tested with an affective perspective-taking task developed by Borke (1971) and modified by Kurdek and Rodgon (1975). The task contains two sets of tests. The first set had four pictures illustrating facial expressions (happy, sad, afraid, and angry) and the purpose of this set was to confirm whether children could match a facial expression to a correct emotion. The second set, the main task, had eight pictures, in which half of the pictures showed the character expressing an emotion that was inappropriate to the situation described and the other half expressing appropriate emotions. The main character was either a boy or a girl depending on the testee's gender. Pictures used in the test were drawn by a professional illustrator. The tester showed the child one picture at a time and asked the child about the main character's emotion in the picture. This test measured how well the child could infer other's emotions, which can be different from the child's. For instance, if the child saw a picture of a boy with a happy facial expression while being chased by a tiger and the child said the boy was happy, then the child scored a point. If the child said the boy was scared, then the child received 0 points. The highest possible score was 8 and the higher the point, the higher the child's affective perspective-taking ability.

\section{Procedure}

A preliminary study was conducted in order to examine the validity and difficulty of tasks used in this study. Six children were tested in October of 2007. The validity and difficulty of the tasks were appropriate and yet the total duration of tests was too long. Thus, we decided to divide the tests into two sessions: the first session was a general language test and the second was a perspective taking task (one session for each day) for the main study. Data for the present study was collected from October 9, 2007 to May 14, 2008. A total of 66 bilingual children were recruited from five international schools or kindergartens in the Busan and Seoul Metropolitan areas. Another 12 bilingual children were recruited through snowball sampling. From 78 bilingual children, 73 were 
balanced bilinguals and five children were excluded from the study. For the comparison group, a total of 60 monolingual children were recruited from two kindergartens in the Seoul metropolitan area. In order to gather the informational background of the participants, a parent questionnaire was collected from participants' parents.

All children were tested individually by a researcher in a quiet room. Korean monolingual children were tested by a Korean native speaker and Korean-English bilingual children were tested by a Korean-English bilingual speaker. PPVT were tested in both languages for both group. In terms of language used in the perspective-taking tasks for the bilingual group, the tasks were conducted in their preferred language (Korean or English). The Korean Picture Vocabulary Test and PPVT- $3^{\text {rd }}$ were conducted first and the perspective-taking tasks were conducted a week later.

In the study, descriptive analysis was conducted to examine bilingual children's cognitive and affective perspective-taking. Twoway ANOVA was then conducted to examine their perspective-taking according to the child's age and gender. For the last, independent sample t-test was conducted to compare cognitive and affective perspective-taking abilities of bilingual children and monolingual children.

\section{Results}

\section{Cognitive perspective-taking task}

Bilingual children's cognitive perspectivetaking task was examined for analysis of age or

Table 3

Bilingual Children's Cognitive Perspective-Taking

\begin{tabular}{cccc}
\hline Age & Sex & $M(S D)$ & $N$ \\
\hline \multirow{2}{*}{4} & Male & $.93(.73)$ & 14 \\
& Female & $.90(.62)$ & 21 \\
& Sub-total & $.91(.66)$ & 35 \\
\hline \multirow{2}{*}{5} & Male & $1.31(.60)$ & 16 \\
& Female & $1.27(.77)$ & 22 \\
& Sub-total & $1.29(.69)$ & 38 \\
\hline Total & & $1.11(.70)$ & 73 \\
\hline
\end{tabular}

Table 4

Difference between Bilingual and Monolingual Children in Cognitive Perspective-Taking

\begin{tabular}{cccccc}
\hline Age & Group & $N$ & $M$ & $S D$ & $t$ \\
\hline \multirow{2}{*}{4} & Bilingual & 35 & .91 & .66 & .61 \\
& Monolingual & 25 & .80 & .76 & .6 \\
\cline { 2 - 5 } 5 & Bilingual & 38 & 1.29 & .69 & .19 \\
& Monolingual & 35 & 1.26 & .74 & \multirow{2}{*}{.331} \\
\hline \multirow{2}{*}{ Total } & Bilingual & 73 & 1.11 & .70 & .78 \\
& Monolingual & 60 & 1.07 & & \\
\hline
\end{tabular}


gender effect. Two way ANOVA revealed a main effect of age $(F=5.28, d f=1, p<.05)$ demonstrating that 5 -year-old bilingual children $(M=1.29, S D=.69)$ performed significantly better than 4-year-old bilingual children $(M=.91$, $S D=.66)$ on cognitive perspective-taking tasks (see Table 3). This result is consistent with previous studies that show that cognitive perspective-taking ability develops with age (Kurdek \& Rodgon, 1975; Selman \& Byrnes, 1974). However, the effect of gender and the interaction between age and gender were not shown in this study. Performances of the bilingual group and monolingual group were compared using independent sample t-test (see Table 4). The result showed that two groups' performances were not significantly different, indicating a lack of bilingual advantage in cognitive perspective taking.

\section{Affective perspective-taking task}

Bilingual children showed greater performance on the affective perspective-taking task than monolingual children. However, there was no significant age or gender effect demonstrating that developmental differences did not exist between 4-year-olds and 5-yearolds. On the other hand, the independent sample $t$-test showed that there were some significant differences in affective perspective-taking between the bilingual group and monolingual group ( $t=4.64, p<.001$ ) (see Table 5 ). The mean of the bilingual group as a whole $(M=$ $7.44, S D=1.26)$ is higher than the mean of monolingual group as a whole $(M=6.40, S D=$ $1.32)$ at $p<.001$. Specifically, in terms of $4-$ year-olds, the bilingual group $(M=7.37, S D=$ 1.09) performed better than the monolingual group $(M=6.28, S D=1.43)$ with significance $(t$ $=3.21, p<.01)$. Similarly, the 5-year-old bilingual group $(M=7.50, S D=1.41)$ outperformed the 5-year-old monolingual group $(M=6.49, S D=1.25)$ with significance $(t=3.26$, $p<.01)$.

\section{Discussion}

The present study was designed to examine perspective-taking ability of bilingual children living in South Korea and to determine whether a bilingual advantage exists in the development of children's perspective-taking ability. More precisely, the study focused on cognitive perspective-taking and affective perspectivetaking of balanced bilinguals. English-Korean bilingual children and Korean monolingual children were recruited from a middle class neighborhood in South Korea and their general language ability was measured by the PPVT- $3^{\text {rd }}$ and Korean PPVT.

The result of the study showed significant difference in affective perspective-taking ability

Table 5

Difference between Bilingual and Monolingual Children in Affective Perspective-Taking

\begin{tabular}{cccccc}
\hline Age & Group & $N$ & $M$ & $S D$ & $t$ \\
\hline \multirow{2}{*}{4} & Bilingual & 35 & 7.37 & 1.09 & \multirow{2}{*}{$3.21^{* *}$} \\
& Monolingual & 25 & 6.28 & 1.43 & \\
\cline { 2 - 5 } 5 & Bilingual & 38 & 7.50 & 1.41 & \multirow{2}{*}{$3.26^{* *}$} \\
& Monolingual & 35 & 6.49 & 1.25 & \\
\hline \multirow{2}{*}{ Total } & Bilingual & 73 & 7.44 & 1.26 & \multirow{2}{*}{$4.64^{* * *}$} \\
& Monolingual & 60 & 6.40 & 1.32 & \\
\hline
\end{tabular}

$* * p<.01, * * * p<.001$ 
between bilingual and monolingual children. Bilingual children performed better in affective perspective-taking tasks than monolingual children. This demonstrates that a bilingual advantage and bilingualism have some effects on the development of affective perspective-taking ability. Affective perspective-taking is the ability to assess and infer another person's emotional state (Underwood \& Moore, 1982). One of the possible reasons for bilingual children's outperformance is that their level of sociolinguistic awareness may be higher than that of monolingual children (Lanza, 1992). Another possible explanation is that bilingual children choose an appropriate language to their partner in their surrounding environment. That is, bilingual children who use both Korean and English need to select which language to use when they encountered new people. At that moment, they need to pay attention not only to their language choice for successful communication, but also to their partner (Goetz, 2003). This kind of interaction continuously occurs in their daily lives, allowing bilingual children to understand not only other's language, but also other's emotions.

In contrast, significant differences were not found in cognitive perspective-taking ability between bilingual and monolingual children, suggesting the lack of bilingual advantage. A possible explanation of this result is the difficulty of tasks for 4 to 5-year-old children. According to Selman-Byrnes's stage of perspective taking (1974), 4 to 5-year-old children are still in an egocentric viewpoint or undifferentiated perspective stage. Based on the theory, children at this stage recognize that the self and others can have different thoughts and feelings, but they frequently confuse the two. Thus, there is a possibility that both bilingual and monolingual participants of this study (4 to 5-year-old children) had difficulty in carrying out the cognitive perspective-taking task that required them to retell a story from their friend's perspective.

Finally, bilingual children's cognitive perspective-taking ability developed with age. Five-year-olds had significantly higher cognitive perspective-taking ability than 4-year-olds. Although children showed some difficulty in cognitive perspective-taking tasks, it was proven that their performance improved with age, indicating that children's cognitive perspectivetaking develops as their cognitive ability matures. However, the result showed that only half of the children solved the task and this suggests that children aged 4 to 5 still have difficulty inferring other's intention. On the other hand, there was no significant difference in bilingual children's affective perspective-taking ability between 4 and 5-year-olds. This is consistent with previous findings that affective perspective-taking is possible at ages under four (Borke, 1971; Bretherton \& Beeghly, 1982; Kreutzer \& Charlesworth, 1973). The result can be interpreted that 4-year-olds have already achieved certain level of affective perspectivetaking, making less room to improve for the 5year-olds in this study.

Despite several findings in the study, we need to take careful considerations in generalizing these findings. First, the study only focused on 4 to 5-year-old children and the range of age is too narrow to generalize the development of bilingual children by age. Although the result of the study shows some developmental difference by age, further studies with larger sample sizes and broader age ranges are needed to examine children's development in the use of bilingualism.

Second, the sample of this study was selected from a similar socioeconomic status in order to control the SES influence over children's language and cognitive development. Since the participants were selected from the middle or upper middle class, their results may have been reflected by a high SES level. Thus, interpretation of the present results should be considered carefully because they may not represent the whole population. Last, the sample of this study was balanced bilinguals who were able to use both English and Korean in natural circumstances. Hence, the finding might be specific to balanced bilinguals and it cannot be taken as definite evidence for children with early English education in South Korea. 
In conclusion, this study has some implications for bilingual studies in South Korea which still is an academic field to be explored further. In particular, the result of the study suggests a bilingual advantage in children's affective perspective-taking. In a time of growing multiculturalism in South Korea, more children will be exposed to bilingual environments and this study can be preliminary data for understanding bilingual children's development. In addition, this study applied stricter standard in defining bilingual children. Until now, most bilingual studies focused on children with early English educational experience or comparison between Korean children in overseas and their monolingual natives in the country. The former cannot be represented as balanced bilinguals because they do not have similar fluency levels in both languages. The latter cannot be generalized in South Korea because the result might reflect some cross-cultural differences. For the first time, this study attempted to find balanced bilingual children through general language ability tests and compared them to Korean-speaking monolingual children in South Korea.

\section{References}

Ausubel, D. P., Sullivan, E. V., \& Ives, S. W. (1980). Theory and problems of child development. $3^{\text {rd }}$ Ed. New York: Grune and Stratton.

Bain, B. (1975). Towards an integration of Piaget and Vygotsky: Bilingual considerations. Linguistics, 16, 5-20.

Ben-Zeev, S. (1977). The influence of bilingualism on cognitive strategy and cognitive development. Child Development, 48, 1009-1018.

Berk, L. E. (2000). Child Development. Boston: Ally and Bacon.

Bialystok, E. (1986). Factors in the growth of linguistic awareness. Child Development, 57, 498-510.

Bialystok, E. (1988). Levels of bilingualism and levels of linguistic awareness. Developmental
Psychology, 24, 560-567.

Bialystok, E., \& Codd, J. (1977). Cardinal limits: Evidence from language awareness and bilingualism for developing concepts of number. Cognitive Development, 12, 85-106.

Borke, H. (1971). Interpersonal perception of young children: Egocentrism or empathy? Developmental Psychology, 5, 262-269.

Bretherton, I., \& Beeghly, M. (1982). Talking about internal states: The acquisition of an explicit theory of mind. Developmental Psychology, 18, 906-921.

Bronfenbrenner, U. (1979). The ecology of human development: Experiments by nature and design. Cambridge, MA: Harvard University Press.

Cummins, J. (1978). Bilingualism and the development of metalinguistic awareness. Journal of Cross-Cultural Psychology, 9, 131149.

Cummins, J., \& Gulutsan, M. (1974). Bilingual education and cognition. The Alberta Journal of Research, 20, 259-269.

Darcy, N. T. (1953). A review of the literature on the effects of bilingualism upon the measurement of intelligence. Journal of Genetic Psychology, 82, 21-57.

Diaz, R. M. (1985). Bilingual cognitive development: Addressing three gaps in current research. Child Development, 55(6), 13761388.

Doherty, M. J., \& Perner, J. (1998). Metalinguistic awareness and theory of mind: Just two words for the same thing? Cognitive Development, 13, 279-305.

Dunn, L., \& Dunn, L. (1997). Peabody Vocabulary Test-Third Edition. Circle Pines, $\mathrm{MN}$ : American Guidance Service.

Flavell, J. H. (1968). The development of roletaking and communication skills in children. New York: Wiley, 1968.

Flavell, J. H., \& Miller, P. H. (1998). Social Cognition. In W. Damon (Ed.), Handbook of child psychology (5th ed., Vol. 2), Cognition, Perception, and Language (pp.851-898). NY: Wiley.

Galambos, S. J., \& Golbin-Meadow, S. (1990). The effects of learning two languages on level 
of metalinguistic awareness. Cognition, 34, 156.

Goetz, P. (2003). The effects of bilingualism on theory of mind development. Bilingualism: Language and Cognition, 6(1), 1-15.

Gopnik, A., \& Wellman, H. M. (1994). The theory-theory. In L. A. Hirschefeld, \& S. Gelman (Eds.), Mapping the mind: Domain specificity in cognition and culture (pp.257293). NY: Cambridge University Press.

Harwood, M. D., \& Farrar, M. J. (2006). Conflicting emotions: The connection between affective perspective taking and theory of mind. British Journal of Developmental Psychology, 24, 401-418.

Hwang, H. S., \& Hwang H. J. (2000). The language development of bilingual children speaking Korean and English, Korean Association of Child Studies, 21(4), 69-79.

Hwang, H. S. (2007). Children's early English education and the factors on their bilingual language development. Korean Journal of Human Ecology, 16(4), 699-710.

Ianco-Worrall, A. (1972). Bilingualism and cognitive development. Child Development, 43, 1390-1400.

Kim, Y. T., Chang, H. S., Lim, S. S., \& Baek, H. J. (1995). Korean Picture Vocabulary Test. Seoul: Seoul Community Rehabilitation Center.

Kreutzer, M. A., \& Charlesworth, W. R. (1973). Facial expressions of infants and children. In E. Paul (Ed.), Darwin and facial expression: $A$ century of research in review (pp.91-168). New York and London: Academic Press, Inc.

Kurdek, L. A. (1978). Perspective taking as the cognitive basis on children's moral development: A review of the literature. Merrill-Palmer Quarterly, 24, 3-28.

Kurdek, L. A., \& Rodgon, M. M. (1975). Perceptual, cognitive and affective perspective-taking in kindergarten through sixth-grade children. Developmental Psychology, 11, 643-650.

Lanza, E. (1992). Can bilingual two-year-olds code-switch? Journal of Child Language, 19, 633-658.

Lee, K. O., Jeon, H, J., \& Park, H. W. (2003).
Cognitive complexity and control in the cognitive ability and language development of 3-to 5-year-old Korean-Chinese bilingual children. Korean Association of Child Studies, 24(6), 1-14.

Lee, K. O., \& Lee, H. R. (2006). The relationship between bilingualism and theory of mind. The Korean Journal of Development Psychology, 19(4), 77-92.

Nam, H. K. (2003). According to bilingual experience and metalinguistic ability of 3year-old and 4-year-old, Master's thesis, Seoul National University, Seoul, Korea.

Peal, E., \& Lambert, W. (1962). The relationship of bilingualism to intelligence. Psychological Monographs, 76, 1-23.

Perner, J. (1991). Understanding the representational mind. Cambridge, MA: MIT Press.

Ricciardelli, L. A. (1992). Bilingualism and cognitive development in relation to threshold theory. Journal of Psycholinguistic Research, 21, 301-316.

Roopnarine, J. L., Lasker, J., Sacks, M., \& Stores, M. (1998). The cultural contexts of children's play. In O. N. Saracho, \& B. Spodek (Eds.), Multiple perspectives on play in early childhood education (pp.194-219). Albany, NY: State University of New York Press.

Sear, D. J. (1923). The effects of bilingualism on intelligence. British Journal of Psychology, 14, 25-38.

Selman, R. L., \& Byrne, D. F. (1974). A structural developmental analysis of levels of role taking in middle childhood. Child Development, 45, 803-806.

Smith, F. (1923). Bilingualism and mental development. British Journal of Psychology, 13, 272-82.

Templin, M. (1957). Certain language skills in children. University of Minnesota Institute Of Child Welfare Monograph Series 26. Minneapolis: University of Minnesota Press.

Vygotsky, L. S. (1962). Thought and language. Cambridge, MA: MIT Press.

Underwood, B. S., \& Moore, E. M. (1982). Perspective taking and altruism. Psychological Bulletin, 91, 143-173. 
Wellman, H. M., Phillips, A. T., \& Rodriguez, T.

Received December 29, 2012 (2000). Young children's understanding of perception, desire, and emotion. Child Revision Received February 7, 2013 Development, 71, 895-912.

Accepted February 8, 2013

Wong-Fillmore, L. (1991). When learning a second language means losing the first. Early Childhood Research Quarterly, 6, 323-346.

Yelland, G. W., Pollard, J., \& Mercuri, A. (1993).

The metalinguistic benefits of limited contact with a second language. Applied Psycholinguistic, 4, 423-444. 